EESTI NSV TEADUSTE AKADEEMIA TOIMETISED. 19. KÖIDE KEEMIA * GEOLOOGIA. 1970, NR. 3

ИЗВЕСТИЯ АҚАДЕМИИ НАУК ЭСТОНСКОЙ ССР. ТОМ 19 ХИМйя * ГЕОЛОГИЯ 1970 , № 3

ВИЙВЕ ВИИРА

\title{
КОНОДОНТЫ ВАРАНГУСКОЙ ПАЧКИ (ВЕРХНИИ ТРЕМАДОК ЭСТОНИИ)
}

В варангуской пачке Северной Эстонии (скважины Тоолсе 420, Тапа, Муналаскме, обнажения Варангу, Кейла-Йоа) обнаружен богатый комплекс конодонтов, который позволяет уточнить возраст данной пачки (Вийра, Кивимяги, Лоог, 1970): Acodus firmus sp. п., *A. tetrahedron Lindström, *Acontiodus? sp., Cordylodus angulatus Pander, C. rotundatus Pander, C. prion Lindström, Distacodus peracutus Lindström, *Distacodus sp., ${ }^{*}$ Drepanodus bisymmetricus sp. n., ${ }^{*} D$. pristinus sp. n., ${ }^{*} D$. aff. subarcuatus Furnish, D. numarcuatus Lindström, D. amoenus Lindström, Drepanodus ? sp. n., ${ }^{*}$ Drepanodus sp., Oistodus inaequalis Pander, O. parallelus Pander, Oneotodus variabilis Lindström, Oneotodus altus sp. n., * Scandodus varanguensis sp. n., S. vitreus sp. n., *Scandodus? sp. n. A, Scandodus? sp. n. B, Scolopodus? peselephantis Lindström.

Отмеченные звездочкой виды характерны төлько для варангуской пачки, остальные встречаются также в ниже- и вышележащих отложениях. Многие из перечисленных видов найдены нами и в тремадокских отложениях скважин Западной Латвии (Стури, Блидене).

При описании видов в
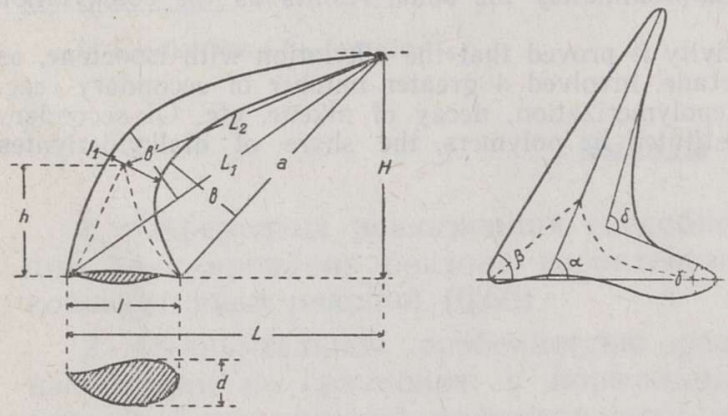

Рис. 1. Термины и измерения конодонта. статье употребляются следующие термины и обозначения (см. рис. 1), частично заимствованные у Т. Москаленко (1967): $H$ - высота конодонта, $h$ - высота базальной полости, $L$ - ширн на конодонта, $L_{1}$ - длина конодонта, $L_{2}$ - длина зубца, $l$ - ширина основания, $l_{1}$ - ширина зубца, $d-$ толщина основания, $\alpha$ - угол наклона зубца к основанию, $\beta$ - передний угол основания, $\gamma-$ - задний угол основания, $\delta$ - задний базальный угол. По аналон гии с аммонитами (Raup, 1967), введено понятие формы образующей кривой, которая характеризует изогнутость конодонта. Различается форма образующей кривой заднего края $\left(S=\frac{b}{a}\right)$ и переднего края $\left(S^{\prime}=\frac{b^{\prime}}{a^{1}}\right)$, где $a^{\prime}=L_{1}$ (рис. 1). Чем больше $S$ и $S^{\prime}$, тем больше изогнутость. Конодонты, имеющие размеры больше 1 мм, считаются большими, а имеюпце размеры меньше 0,4-0,5 мм - маленькими. Базальная полость 
является глубокой, когда высота больше ширины, и неглубокой, когда высота меньше ширины. Если угол наклона зубца к основанию $\alpha=90$, то конодонт прямой, если $\alpha=60 \div 90^{\circ}$, то - слабонаклоненный, если $\alpha=30 \div 60^{\circ}$, то - умеренно наклоненный, и если $\alpha<30^{\circ}$, то конодонт считается сильнонаклоненным.

Коллекция описанных конодонтов хранится в Геологическом музее Института геологии АН ЭССР в Таллине.

\section{ОПИСАНИЕ КОНОДОНТОВ}

\section{Род Acodus Pander, 1856 \\ Acodus firmus sp. n. \\ (Таблица, фиг. 9; рис. 2)}

Голотип: Экз. Cn 52, таблица, фиг. 9. Цератопигевый горизоіт, варангуская пачка $\left(A_{I I I} V\right)$. Северная Әстония, скв. Тоолсе 420 , интервал $18,35-18,60 \mathrm{M}$.

Д и а гн о 3. Сильнонаклоненный конусовидный конодонт с длинным зубцом и округленным боковым ребром, более резко выступающим в базальной части. Передний край основания сплющен и повернут внутрн.

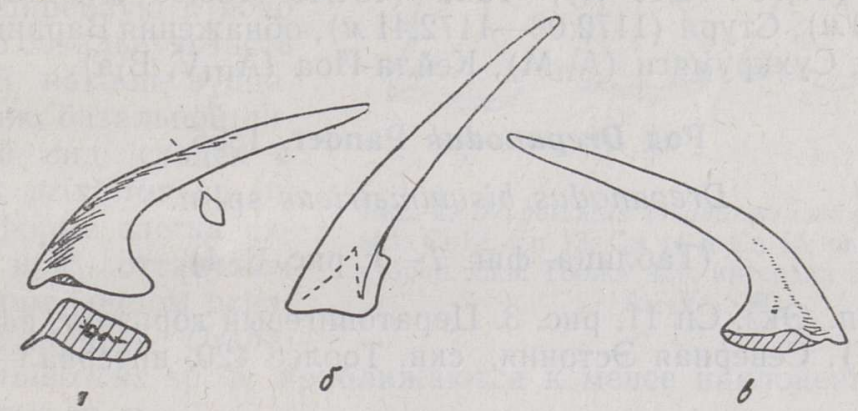

Рис. 2. Acodus firmus sp. п. Левый экз. Cn 1, виды с боковых $(a, b)$ и передней $(б)$ сторон. Скв. Муналаскме, интервал $73,55-73,70 \mu, \mathrm{A}_{I I I} \mathrm{~V} . \times 30$.

О п и с а н ие. Несимметричные конодонты средних и больших размеров, сильнонаклоненные, с основанием, на котором наиболее четко выступает признак данного рода (боковое ребро). Конодонты не просвечивающиеся, массивного облика.

Наклон зубца к основанию $\alpha \cong 25 \div 30^{\circ}$. Изогнутость заднего края $S \cong 0,23$, переднего края $S^{\prime} \cong 0,14$.

Сбоку основание имеет треугольный вид и по высоте составляет примерно $1 / 4$ всей длины конодонта. Углы основания: $\beta \cong 50 \div 65^{\circ}, \gamma \cong 45 \div$ $\div 50^{\circ}$ и $\delta \cong 70 \div 80^{\circ}$. Внешняя сторона основания угловато-выпуклая с округленным ребром посередине. От основания к зубцу ребро постепенно переходит в округленную выпуклость. Внутренняя сторона основания умеренно выпуклая, но с вогнутостью в передней части. Передний край оттянутый, сплющенный и обращенный внутрь.

Зубец длинный, прямой, с острыми передним и задним краями. Боковые поверхности несимметричные - наружная более выпуклая, чем внутренняя. Наибольшая выпуклость наружной стороны располагается посередине или ближе к переднему краю, на внутренней стороне она 
ближе к заднему краю. К верхушке зубца выпуклость сторон постепенно уменьшается.

Базальная полость заполняет все основание и имеет коническую форму. Из-за довольно толстой стенки контуры полости плохо видимы.

Очертание базальной полости неправильно-треугольное с округленным задним и острым передним концами, с угловатой внешней и вы пукло-вогнутой внутренней сторонами.

Заполнение базальной полости встречается часто и имеет черный цвет. Иногда сбоку заметны неясные полосы заполнения, параллельныс нижней поверхности основания.

И з менчи в ость выражается в различной степени выпуклости боковых сторон как зубца, так и основания. Изменчива также массивность конодонта.

С р а в н ен ие. Acodus firmus sp. п. по общей форме напоминает Dre. panodus cf. subarcuatus Furnish, описанный M. Линдстремом (Lindström, 1955), но отличается наличием бокового ребра, хотя и у приведенного M. Линдстремом экземпляра (табл. II, фиг. 44) видна реберноподобная выпуклость.

Р аспространение и воз раст. Прибалтика; пакерортский, цератопигевый горизонты, низы хуннебергского подгоризонта.

Матери ал и местонахождение. Около 70 экз. (правыхи левых), в основном с обломанными верхушками зубцов. Скважины Тоолсе $420(17,90-19,10$ м), Тапа $(134,40-135,05$ м), Муналаскме $\left(73,45-73,70\right.$ M), Стури $(1172,08-1172,41 M)$, обнажения Варангу $\left(\mathrm{A}_{I I I} \mathrm{~V}\right)$. Ягала (B $\mathrm{I})$, Сухкрумяги $\left(\mathrm{A}_{\mathrm{II}} \mathrm{M}\right)$, Кейла-Коа $\left(\mathrm{A}_{\mathrm{III}} \mathrm{V}, \mathrm{B}_{\mathrm{I}} \mathrm{a}\right)$.

\section{Род Drepanodus Pander, 1856}

\section{Drepanodus bisymmetricus sp. $\mathrm{n}$.}

(Таблица, фиг. $1-5$; рис. 3,4 )

Гол о т и п. Экз. Cn 11, рис. 3. Цератопигевый горизонт, варангуская пачка $\left(\mathrm{A}_{\mathrm{III}} \mathrm{V}\right)$. Северная Эстония, скв. Тоолсе 420 , интервал - 18,85 19,10 M.

Д и агн о з. Прямой конусовидный конодонт, характеризующийся кроме симметричности боковых сторон еще значительным подобием передней и задней половин конодонта. Зубец лезвиеобразный, с острыми краями, основание низкое.
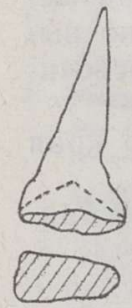

0

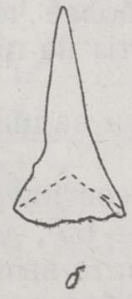

Рис. 3. Drepanodus bisymmetricus sp. п. Голотип Cn 11, виды с боковых сторон $(a, 6)$. Скв. Тоолсе 420, интервал 18,85$19,10 \mu, \mathrm{A}_{I I I}$ V. $\times 46$.

О п и с а н и е. Конодонты средних и малых размеров, сбоку имеют вид высокого треугольного колпачка. Конодонты прямые и при отсутствии ребер у основания трудно определить переднюю и заднюю стороны. Наклон конодонта минимальный, $\alpha=85 \div 90^{\circ}$. Переход зубца в основание едва намечен незначительным изгибом заднего края. $\delta=150 \div 160^{\circ}$. Изогнутость минимальная: $S \cong 0,08$, $S^{\prime} \cong 0,03$.

Зубец уплощенный и имеет острые передний и задний края. Сильную остроту краев подчеркивают часто обломанные участки. Зубец заканчивается острой, симметричной вершиной. Боковые поверхности зубца одинаково слабо выпуклые. 
Основание низкое (до $1 / 5$ высоты конодонта), расширяющееся книзу, с округленно-острыми передним и задним краями. Ширина основания равняется ширине конодонта. Стенки основания тонкие. На боковых сторонах основания, в его передней части, иногда имеются короткие ребра (пс одному на каждой стороне). Часто передний конец основания, особенно при наличии ребер, оттянут вниз. Углы основания: $\beta \cong 70^{\circ}, \gamma \cong 65^{\circ}$.

Базальная полость имеет форму низкого уплощенного конуса, вершина которого занимает срединное положение. Базальная линия более или менее правильно округленно-прямоугольная, имеет наибольшую ширину близ переднего конца, на месте расположения ребер. Задний конещ более округленный. Ширина основания в два раза больше его толщины.

Из менч и в ость. Наиболее заметным изменчивым признаком является степень выраженности ребер, которые могут и отсутствовать в передней части основания. В некоторой степени изменчивы отношение высоты конодонта к ширине основания (рис. 4), очертание базальной линии и оттянутость вниз переднего конца основания.

С ра в н ени е. Среди небольшого количества прямых конодонтов описываемый вид сравним с Dre. panodus erectus (Stauffer, 1935). Но последннй имеет сильно расширенную и ясно выделенную базальную часть и заметный наклон зубца. По очертанию базальной линии данный вид сходен с Drepanodus pristinus sp. n. По общей форме слегка наклоненные и с оттянутым вниз передним концом осно-

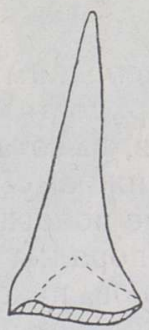

0

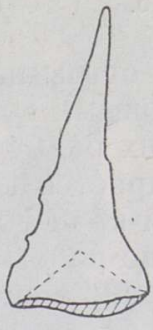

$\delta$

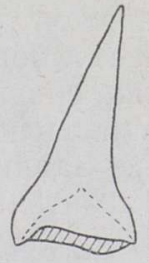

6

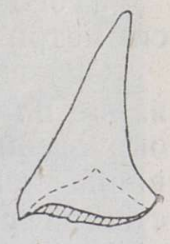

Pис. 4. Drepanodus bisymmetricus sp. n. $a-2-$ эк3. Cn12, Cn 13, Cn 14 и Cn 15, виды с боковыж сторон. Скв. Тоолсе 420 , интервал 18,85-19,10 м, AIIIV. $\times 46$.

\title{
вания экземпляры Drepa-
}

nodus bisymmetricus sp. п. приближаются к менее наклоненным Drepanodus pristinus $\mathrm{sp}$. $\mathrm{n}$.

Р аспространение и возраст. Северная Әстония; варангуская пачка цератопигевого горизонта $\left(\mathrm{A}_{\mathrm{III}} \mathrm{V}\right)$.

Матери л и местонахождение. Около 50 экз. средней сохранности. Скважины Тоолсе $420(17,00-19,10$ м), Тапа $(134,10-$ 135,05 м), Муналаскме $\left(72,80-73,55\right.$ м) и обн. Варангу $\left(\mathrm{A}_{\mathrm{III}} \mathrm{V}\right)$.

\section{Drepanodus pristinus sp. $\mathrm{n}$.}

\author{
(Таблица, фиг. 7,8 ; рис. 5,6 )
}

Голоти п. Экз. Сn 16, рис. 5. Цератопигевый горизонт, варангуская пачка $\left(\mathrm{A}_{\mathrm{III}} \mathrm{V}\right)$, Северная Эстония, скв. Тоолсе 420 , интервал $16,80-17,00$ м.

Д и агноз. Простой симметричный конодонт с прямым слабонаклоненным зубцом и расширенным основанием, имеющим округленные передний и задний концы.

О пи сани е. Конодонты средних и малых размеров (до 0,7 мм), слабонаклоненные $\left(\alpha \cong 70^{\circ}\right)$. Изогнутость переднего края меньше $\left(S^{\prime} \cong 0,06\right)$ заднего $(S \cong 0,13)$.

Переход зубца в основание намечен ясным изгибом заднего края конодонта, $\delta=120 \div 125^{\circ}$. 


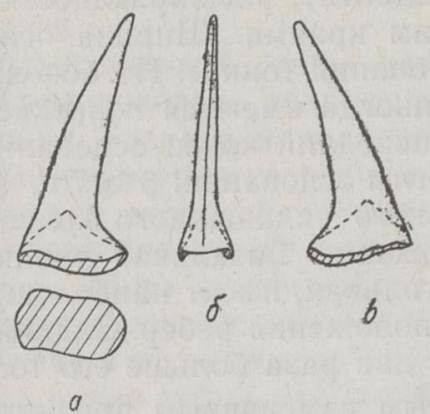

Рис. 5. Drepanodus pristinus sp. п. Голотип Cn 16, виды с боковых $(a, b)$ и передней (б) сторон. Скв. Тоолсе, интервал $16,80-17,00$ м, $A_{\text {III }} V$. $\times 46$.
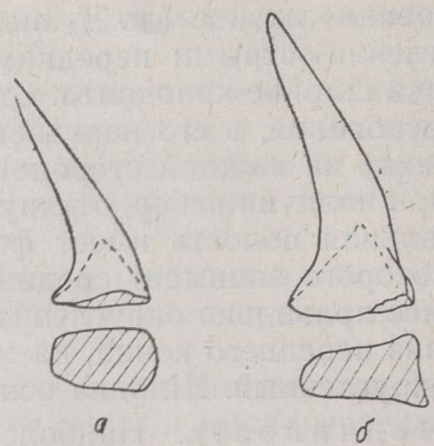

Puc. 6. Drepanodus pristinus sp. п. Экз. Сn 17 и $\mathrm{Cn} 18$. Скв. Тоолсе $420, a-$ интервал $18,85-19,10$ м, бинтервал $16,30-16,50 \quad \boldsymbol{M}$, AIIV. $\times 46$.

Зубец прямой, с острыми передним и задним краями и выпуклыми симметричными боковыми поверхностями.

Основание средних размеров, высота немного меньше ширины. Основание плавно расширяется к нижнему краю, передний и задний концы округленные. Задний край более пологий, чем передний, хотя углы основания приблизительно равные, порядка 70-80․ Приблизительное равенство углов обусловлено неровной нижней поверхностью конодонта. Б передней- части основания могут присутствовать ребра, по одному на каждой боковой стороне. У самого нижнего края ребра могут быть как едва заметными, так и резкими, доходящими до высоты изгиба заднего края (рис. 6).

Базальная полость коническая, слегка сплющенная с боков. Вершина расположена немного ближе к переднему краю.

\section{Т А Б Л И А}

(Увеличение $\times 65$ )

Фиг. 1-5. Drepanodus bisymmetricus sp. n. 1 - типичный экз. Cn $41 ; 2,3$ - слегка наклоненные экз. Cn, 42 и Cn 43; 4,5 - переходные к Drepanodus pristinus sp. п. экз. Cп 44 и $\mathrm{Cn} 45$. Обн. Варангу, AІIIV.

Фиг. 6. Distacodus peracutus Lindström. Экз. Cn 47. Обн. Варангу, $\mathrm{A}_{\mathrm{III}} \mathrm{V}$.

Фуг. 7, 8. Drepanodus pristinus sp. п. Экз. Cn 48 и Cn 49. Обн. Варангу, $A_{I I I V}$.

Фиг. 9. Acodus firmus sp. n. Экз. Cn 52. Скв. Тоолсе 420, интервал $18,35-18,60$ м, $\mathrm{A}_{\text {III }} \mathrm{V}$. Фиг. 10. Oneotodus altus sp. п. Әкз. Cn 53. Обн. Варангу, $\mathrm{A}_{I I I} \mathrm{~V}$.

Фиг. 11, 12. Scandodus varanguensis sp. п. Правый и левый экз. Сп 57 и Cn 58. Обн. Варангу, $\mathrm{A}_{\text {III }} \mathrm{V}$.

Ф;иг. 13, 14. Scandodus vitreus sp. п. Правый и левый экз. $\mathrm{Cn} 59$ и $\mathrm{Cn} 60$. Обн. Варангу, AIIIV.

Фиг. 15, 21, 22. Acodus tetrahedron Lindström. 15 - левый экз. Сп 65, 21, 22 - правые экз. Сn 63 и $\mathrm{Cn}$ 64. Обн. Варангу, $\mathrm{A}_{\text {III V}}$.

Фит 16, 17. Drepanodus sp. Экз. Сn 68 и Cn 69. Обн. Варангу, AIIV.

Фиг 18, 19. Drepanodus aff. subarcuatus Furnish. Правый и левый экз. Сn 71 и Cn 72 . Обн. Варангу, $\mathrm{A}_{I I I} \mathrm{~V}$.

Фиг. 20. Drepanodus ? sp. n. Экз. Cn 76. Обн. Варангу, $\mathrm{A}_{\text {III V. }}$

Фиг. 23. Scandodus ? sp. п. В. Әкз. Сп 77. Обн. Варангу, АIIIV. 


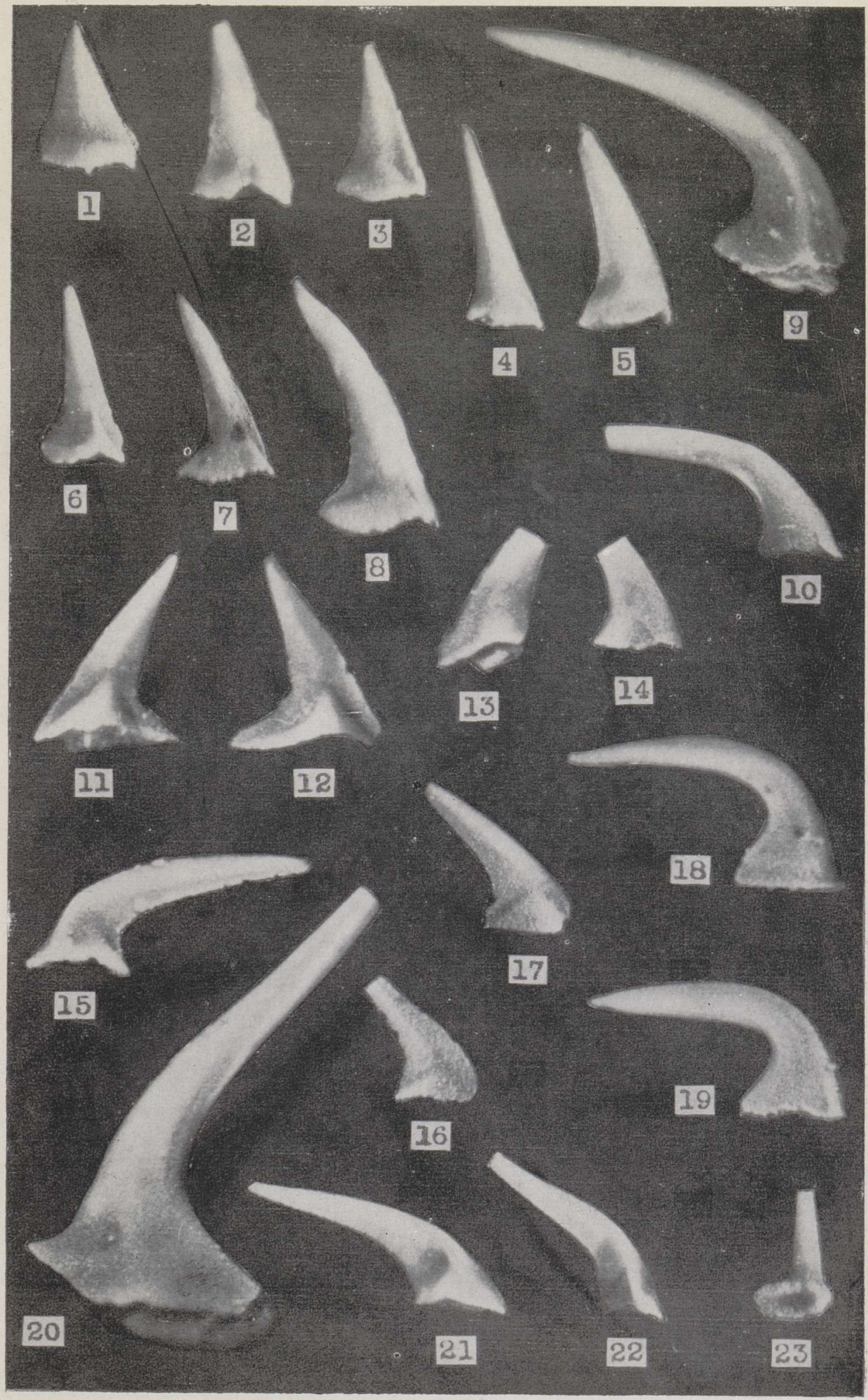



Очертание базальной линии округленно-прямоугольное. Задний конец всегда округленный, передний более угловатый, особенно при наличии ребер.

И з менчи в ость проявляется в изгибе конодонта (в основном переднего края), а также в наличии или отсутствии ребер.

С равнен ие. От наиболее близкого Drepanodus suberectus (Branson, Mehl, 1933) данный вид отличается более высоким основанием и другим очертанием базальной линии, а также наличием ребер. Сравнение с Drepanodus bisymmetricus sp. п. приведено при описании последнего.

Р асп рост ранени и и воз раст. Северная Эстония; варангуская пачка цератопигевого горизонта $\left(\mathrm{A}_{\mathrm{III}} \mathrm{V}\right)$.

Материал и местонахождение. Около 60 экз. средней сохранности. Скважины Тоолсе $420(16,30-19,10$ м), Тапа $(134,10-$ 135,05 м), Муналаскме $\left(73,05-73,45\right.$ м) и обн. Варангу $\left(\mathrm{A}_{\mathrm{III}} \mathrm{V}\right)$.

\section{Род Oneotodus Lindström, 1955}

\section{Oneotodus altus sp. n.}

(Таблица, фиг. 10; рис. 7)

Г ол о ти п. Экз. Cn 23, рис. 7. Цератопигевый горизонт, варангуская пачка $\left(\mathrm{A}_{\mathrm{III}} \mathrm{V}\right)$. Северная Эстония, скв. Тоолсе 420, интервал 18,8519,10 M.

Рис. 7. Oneotodus altus sp. п. Голотип $\mathrm{Cn}$ 23. Скв. Тоолсе 420 , интервал $18,85-19,10$ м, AIIIV. $\times 46$.

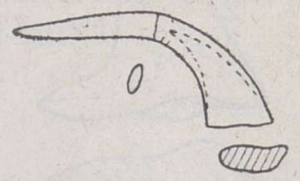

Диагноз. Дрепанодусообразный конодонт, плавно изогнутый, сильнонаклоненный, с высоким основанием и округленными передним и задним краями.

О п и сани е. Средних и малых размеров рогообразные конодонты, симметричные или почти симметричные, уплощенные в боковом направлении. Наклон зубца $\alpha=5 \div 20^{\circ}$.

Переход зубца в основание постепенный, плохо заметный. Изогнутость плавная: $S^{\prime} \cong 0,23, S \cong 0,24$. Угол $\delta=100 \div 105^{\circ}$.

Зубец почти прямой и охватывает примерно половину всей длины конодонта. Боковые поверхности равномерно и умеренно выпуклые. Передний и задний края округленные.

Основание высокое, отклоненное назад, плавно изогнутое. Высота его составляет от $1 / 2$ до $3 / 4$ высоты конодонта. Углы основания: $\beta=75 \div$ $\div 80^{\circ}, \gamma=85 \div 90^{\circ}$. Прозрачность основания отчерчивает его от непрозрачного зубца. Основание имеет выпуклые боковые поверхности и округленные края.

Базальная полость высокая, имеет форму уплощенного конуса с отклоненной назад вершиной.

Очертание базальной полости неправильно-овальное. Наблюдается базальное заполнение черного цвета.

Из мен чи в ост и подвержены выпуклость боковых сторон, высота и наклон основания.

С р а в н е н и е. Среди онеотодусов близкие виды неизвестны. По общей форме данный вид немного приближается к представителям родов Panderodus (высокое основание) и Drepanodus (симметричные боковые 
поверхности). Экземпляры с более низкой базальной полостью напоминают переднюю часть (без второстепенных зубчиков) Cordylodus angulatus (Pander, 1856).

Р аспространение и возраст. Прибалтика; пакерортский гон ризонт $\left(\mathrm{A}_{\mathrm{II}}\right)$ и варангуская пачка цератопигевого горизонта $\left(\AA_{\mathrm{III}} \mathrm{V}\right)$.

Матери ал и местонахождение. Около 80) экз. различной сохранности. Скважины Тоолсе $420(16,30-19,10$ м $)$, Тапа $(134,40-$ 135,05 м ), Муналаскме $(73,30-73,55$ м), Стури $(1172,08$ м) и обнажения Варангу $\left(\mathrm{A}_{\mathrm{III}} \mathrm{V}\right)$ и Сухкрумяги $\left(\mathrm{A}_{\mathrm{II}} \mathrm{M}\right)$.

\section{Род Scandodus Lindström, 1955}

Scandodus varangtuensis sp. $\mathrm{n}$.

(Таблица, фиг. 11, 12; рис. 8,9 )

Г олоти п. Правый экз. Сn 26, рис. 8. Цератопигевый горизонт, варангуская пачка $\left(\mathrm{A}_{\text {III }} \mathrm{V}\right)$. Северная Эстония, скв. Тоонсе 420 , интервал $18,85-19,10 \mu$.

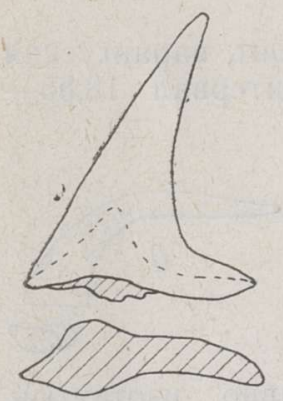

a

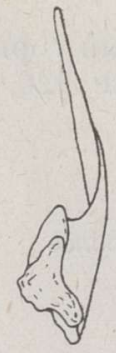

$\delta$

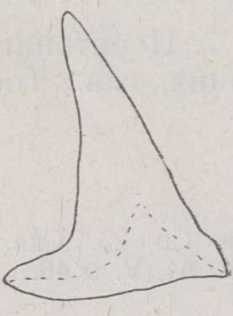

6
Рнс. 8. Scandodus varanguensis sp. n. Голотип $\mathrm{Cn} 26$, виды с боковых $(a, 8)$ и задней (б) сторон. Скв. Тоолсе 420, интервал 18,85-19,10 м, AIIV. $\times 46$.

Д и аг оз. Елоский Scandodus с широким основанием и слегка скрученным зубцом. Базальная часть свнутренней стороны выпуклая.

О пи с а ни е. Несимметричные конодонты средней величины $(0,4-0,8 м \mu)$, тонкие, с широким, оттянутым назад основанием. Ширина основания являетея и шириной конодонтан.

\section{Зубец слабонаклонен-} ный, $\alpha \cong 65^{\circ}$. Зубец скручен по спирали примерно до чет.

верти оборота: Переднийі край конодонта почти прямой $\left(S^{\prime} \cong 0,05\right)$. Задний край более изогнутый, $S=0,23 \div 0,24$. Задний базальный угол $\delta=100 \div 110^{\circ}$.

Основание большое, сильно вытянутое в передне-заднем направлении. Угол $\beta=55 \div 65^{\circ}, \gamma=25 \div 50^{\circ}$. Внешняя сторона основания слабовыпуклая $\mathrm{c}$ незначительной вогнутостью в своей задней части. Внутренняя сторона выпуклая, наибольшая выпуклость у базального края на: ширине верхушки базальной полости. Основание переходит постепенно в. зубец. Последний по длине равен ширине основания или меньше ее. Передний и задний края зубца весьма острые. Боковые поверхности слабовыпуклые, причем внутренняя обычно более выпукла. Поперечное сечение зубца имеет форму тонкой выпуклой линзы.

Базальная полость низкая, конусовидная, с верхушкой в передней. трети основания. Высота базальной полости составляет $1 / 2-1 / 3$ еe ширины. Очертание базальной полости имеет вид вытянутого овала неправильной формы. Наружный край слегка вогнутый, внутренний - выпуклый. Задний конец более округленный, чем передний.

Из менчи вость. Наибольшая изменчивость наблюдается в размерах базальной части и в отношении ширины основания к длине коно- 
донта, последнее колеблется от $2 / 5$ до $4 / 5$ (рис. 9 ). Преобладают формы с более широким основанием. Изменчивы также степень скрученности конодонта́ и величина бокового вздутия в базальной части.

С р а в н ен и е. Неко. торые экземпляры с длинным задним концом основания и с маленьким задним базальным углом сходны с Oistodus inaequalis Pander.

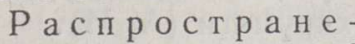
ние и возраст. Cеверная Әстония; варангуская пачка цератопигевого горизонта $\left(\mathrm{A}_{\mathrm{III}} \mathrm{V}\right)$.

М а ери ал и ме стон ахожд ен ие. Более 100 правых и левых экз. различной сохранности. Скважины Тоолсе 42C $(16,30-19,10$ м), Тапа $(134,80-135,05$ м), Муналаскме $(73,55-$ 73,70 м) и обнажения Варангу $\left(\mathrm{A}_{I I I} \mathrm{~V}\right)$ и Кейла-Коа $\left(\mathrm{A}_{1 \mathrm{II}} \mathrm{V}\right)$.

Scandodus vitreus sp. n.

(Таблица, фиг. 13,14 ; рис. 10)

Гол өти п. Левый эк3. Сn 33, рис. 10. Цератопигевый горизонт, варангуская пачка $\left(\mathrm{A}_{\mathrm{III}} \mathrm{V}\right)$. Северная Әстония, скв. Тоолсе 420 , интервал $18,85-19,10 \mu$.

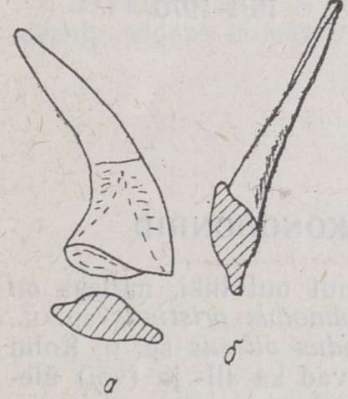

Рис. 10. Scandodus vitreus sp. n. Голотип Cn 33. Скв. Тоолсе 420 , интервал $18,85-19,10$ м, $\mathrm{A}_{\text {III }} \mathrm{V}$. $\times 46$.

Д и а гно з. Умеренно наклоненный Scandodus с большим просвечивающимся основанием. Конодонт равномерно расширяется книзу.

О пи с ан и е. Средних и малых размеров несимметричные конодонты, отклоненные назад и внутрь. $\alpha \cong 45^{\circ}$.

Переход зубца в основание постепенный, с равномерным расширением книзу. Передний и задний края зубца острые. Изогнутость переднего края равномерная, $S^{\prime} \cong 0,12$. Задний край имеет $S=0,14 \div 0,19$; наибольший изгиб на середине высоты конодонта. Задний базальный угол $\delta=110 \div 120^{\circ}$. Наружная боковая поверхность плоская, внутренняя - плоско-выпуклая с округленным ребром.

Основание большое, занимает половину высоты и ширины конодонта Основание, как и весь конодонт, умеренно отклонено назад. $\gamma \cong 65^{\circ}$, $\beta \cong 45^{\circ}$, но эти углы могут колебаться в значительных пределах. Выпуклость внутренней поверхности основания увеличивается книзу, достигая нанбольшей степени у нижнего края ближе к заднему концу. Основание 
просвечивается, ясно видны контуры базальной полости. Последняя имеет форму неправильного конуса, отклоненного слегка назад и внутрь. Қонтур базальной линии треугольно-овальный. Базальное заполнениє черного цвета.

И з мен чи в ость наблюдается в различной степени у следующих признаков: высота и ширина основания, изогнутость конодонта (в основном заднего края), степень выступа базальной части.

С р а в н ен и е. Некоторые экземпляры с более низким и широким основанием напоминают переднюю часть (без второстепенных зубчиков) Cordylodus prion Lindström.

Р а сп рост ранени е и воз раст. Северная Эстония; маардуская пачка пакерортского горизонта $\left(\mathrm{A}_{\mathrm{II}} \mathrm{M}\right)$, варангуская пачка цератопигевого горизонта $\left(\mathrm{A}_{\mathrm{III}} \mathrm{V}\right)$.

Матери ал и местон ахождени е. Около 50 экз. (правых и левых) удовлетворительной сохранности. Скважины Тоолсе 420 (17,9019,10 м), Тапа $(134,65-135,05$ м), Муналаскме $(73,30-73,70$ м ), обнажения Варангу $\left(\mathrm{A}_{\mathrm{III}} \mathrm{V}\right)$, Кейла-Йоа $\left(\mathrm{A}_{\mathrm{III}} \mathrm{V}\right)$ и Сухкрумяги $\left(\mathrm{A}_{\mathrm{II}} \mathrm{M}\right)$.

\section{Л И ТЕ Р А Т У Р А}

В и й р а В., К и в и м яг и Э., Л о ог А. 1970. О литологии и возрасте варангуской пачки (тремадок Северной Эстонии). Изв. АН ЭССР, Хим. Геол., 19, 2.

М о ска л енко Т. А. 1967. Конодонты чуньского яруса (нижний ордовик) рек Мойеро и Подкаменная Тунгуска. В сб.: Новые данные по биостратиграфии нижнего палеозоя Сибирской платформы. Из-во «Наука».

Branson E. B., Meh1 M. C. 1933. Conodonts from the Jefferson City (lower Ordovician) of Missóuri. Univ. Missouri Studies, 8, No. 1.

L in d ström M. 1955. Conodonts from the lowermost Ordovician strata of south-central Sweden. Geol. Fören. Förh., 76.

P a n der C. H. 1856. Monographie der fossilen Fische des silurischen Systems der russisch-baltischen Gouvernements. Akad. Wiss. St.-Petersburg.

R a u p D. M. 1967. Geometric analysis of shell coiling: coiling in ammonoids. J. Palaeont., 41,1 .

St a uffer C. R. 1935. The conodont fauna of the Decorah Shale (Ordovician). J. Palaeont., $9 ., 7$.

$\begin{array}{cc}\text { Ннститут геологии } & \text { Поступила в редакцию } \\ \text { Академии наук Эстонской ССР } & 16 / \mathrm{I} 1970\end{array}$

VIIVE VIIRA

\section{VARANGU KIHISTIKU (EESTI ULEMTREMADOK) KONODONDID}

Põhja-Eestis levivast varangu kihistikust kirjeldatakse kuut uut liiki, milleks on Acodus firmus sp. n., *Drepanodus bisymmetricus sp. n., * Drepanodus pristinus sp. n., Oneotodus altus sp. n.. * Scandodus varanguensis sp. n., Scandodus vitreus sp. n. Kolm neist $\left(^{*}\right)$ on iseloomulikud ainult varangu kihistikule, teised esinevad ka all- ja (või) ülevalpool lasuvates kihtides.

\section{VIIVE VIIRA}

\section{CONODONTS OF THE VARANGU MEMBER (ESTONIAN UPPER TREMADOC)}

The author describes six new species from the Varangu Member, distributed in North Estonia: Acodus firmus sp. n., *Drepanodus bisymmetricus sp. n., *Drepanodus pristinus sp. n., Oneotodus altus sp. n., * Scandodus varanguensis sp. n., Scandodus vitreus sp. n. Three of them $\left({ }^{*}\right)$ are typical of the Varangu Member, only, whereas the others also occur in both the underlying and/or the overlying strata. 


\section{Acodus firmus sp. n.}

Hol ot y pe. Specimen Cn 52, Ceratopyge Stage, Varangu Member (AIIIV), Toolse 420) ioring, depth $18.35-18.60 \mathrm{~m}$, North Estonia. Pl., fig. 9.

$\mathrm{D}$ i a $\mathrm{g}$ n o s i s. A recurved cone-like conodont with rather long cusp and rounded laterai costa that is more accentueted basally. The sharp anterior edge of base flaring to one side.

\section{Drepanodus bisymmetricus sp. $\mathrm{n}$.}

Hol ot y p e. Specimen Cn 11, Ceratopyge Stage, Varangu Member (AIIV), Toolse 420) boring, depth $18.85-19.10 \mathrm{~m}$, North Estonia. Text-fig. 3.

D i a g nosis. An erect cone-like conodont, characterized besides symmetrical latera] faces, by considerable similarity of the anterior and posterior parts of conodont. Cusp rather thin and sharp-edged, base shallow.

\section{Drepanodus pristinus sp. $\mathrm{n}$.}

H o lot y p e. Specimen Cn 16, Ceratopyge Stage, Varangu Member (AIIIV), Toolse 420 boring, depth $16.80-17.00 \mathrm{~m}$, North Estonia. Text-fig. 5 .

Di a gnosis. A simple symmetrical conodont with slightly proclined cusp and expanded base. In cross-section the latter is oval, with rounded anterior and posterior ends.

\section{Oneotodus altus sp. $\mathrm{n}$.}

H o l o t y p e. Specimen Cn 23, Ceratopyge Stage, Varangu Member ( $A_{I I I}$ V), Toolse 420 koring, depth $18.85-19.10 \mathrm{~m}$, North Estonia. Text-fig. 7 .

Di a g n o s is. An evenly curved Drepanodus-like conodont with high base and rounded anterior and posterior edges.

\section{Scandodus varanguensis sp. n.}

Holoty pe. Dextral specimen Cn 26, Ceratopyge Stage, Varangu Member (AIIV), Toolse 420 boring, depth $18.85-19.10 \mathrm{~m}$, North Estonia. Text-fig. 8.

D i a g n o s is. A strongly compressed Scandodus with wide base and slightly twisted cusp. The base is convex at the interior side.

\section{Scandodus vitreus sp. $\mathrm{n}$.}

Hol ot y p e. Sinistral specimen Cn 33, Ceratopyge Stage, Varangu Member (AIIVi, Toolse 420 boring, depth $18.85-19.10 \mathrm{~m}$, North Estonia. Text-fig. 10 .

$\mathrm{Di}$ a g nos is. A moderate reclined Scandodus with translucent base. The conodoni evenly widens downwards. 